BMJ Open

Diabetes

Research

\& Care

\section{Evaluation of AUSDRISK as a screening tool for lifestyle modification programs: international implications for policy and cost-effectiveness}

To cite: Malo JA, Versace VL, Janus ED, et al. Evaluation of AUSDRISK as a screening tool for lifestyle modification programs: international implications for policy and cost-effectiveness. BMJ Open Diabetes Research and Care 2015;3:e000125

doi:10.1136/bmjdrc-2015000125

Received 20 June 2015 Revised 2 September 2015 Accepted 7 September 2015

CrossMark

For numbered affiliations see end of article.

\section{Correspondence to}

Dr Jonathan A Malo;

jonathan.malo@greaterhealth. org

\section{ABSTRACT}

Objective: To evaluate the current use of Australian Type 2 Diabetes Risk Assessment Tool (AUSDRISK) as a screening tool to identify individuals at high risk of developing type 2 diabetes for entry into lifestyle modification programs.

Research Design and Methods: AUSDRISK scores were calculated from participants aged 40-74 years in the Greater Green Triangle Risk Factor Study, a crosssectional population survey in 3 regions of Southwest Victoria, Australia, 2004-2006. Biomedical profiles of AUSDRISK risk categories were determined along with estimates of the Victorian population included at various cut-off scores. Sensitivity, specificity, positive predictive value (PPV), negative predictive value, and receiver operating characteristics were calculated for AUSDRISK in determining fasting plasma glucose $(\mathrm{FPG}) \geq 6.1 \mathrm{mmol} / \mathrm{L}$.

Results: Increasing AUSDRISK scores were associated with an increase in weight, body mass index, FPG, and metabolic syndrome. Increasing the minimum cut-off score also increased the proportion of individuals who were obese and centrally obese, had impaired fasting glucose (IFG) and metabolic syndrome. An AUSDRISK score of $\geq 12$ was estimated to include $39.5 \%$ of the Victorian population aged 40-74 (916 000), while a score of $\geq 20$ would include only $5.2 \%$ of the same population (120 000). At AUSDRISK $\geq 20$, the PPV for detecting $F P G \geq 6.1 \mathrm{mmol} / \mathrm{L}$ was $28.4 \%$.

Conclusions: AUSDRISK is powered to predict those with IFG and undiagnosed type 2 diabetes, but its effectiveness as the sole determinant for entry into a lifestyle modification program is questionable given the large proportion of the population screened-in using the current minimum cut-off of $\geq 12$. AUSDRISK should be used in conjunction with oral glucose tolerance testing, fasting glucose, or glycated hemoglobin to identify those individuals at highest risk of progression to type 2 diabetes, who should be the primary targets for lifestyle modification.

\section{INTRODUCTION}

The incidence of type 2 diabetes mellitus is rising globally and the prevalence in

\section{Key messages}

- Type 2 diabetes risk assessment tools should be used in conjunction with fasting glucose, oral glucose tolerance testing, or glycated hemoglobin to determine entry into lifestyle modification programs.

- Cut-off scores of type 2 diabetes risk assessment tools for screening into lifestyle modification programs and further testing should be chosen with knowledge of the proportion of the population at different risk scores.

- Lowering entry criteria for lifestyle modification programs to reduce risk of type 2 diabetes is likely to decrease the impact of the program as well as the cost-effectiveness.

Australia is estimated to reach over 2.3 million by $2035 .^{1}$ Annual expenditure on diabetes in Australia already amounts to over A $\$ 14$ billion in direct costs and government subsidies, ${ }^{2}$ therefore population and highrisk strategies are required to mitigate future disease burden.

A number of studies aimed at prevention of type 2 diabetes have included only those with disorders of abnormal glucose metabolism. ${ }^{3-5}$ Individuals with impaired glucose tolerance (IGT) and impaired fasting glucose (IFG), are among the highest risk for developing type 2 diabetes, with an annual incidence of $5-10 \%$ across various categories of IGT or IFG. ${ }^{6}$ Such disorders are reversible, and trials have demonstrated that intensive lifestyle modification programs can successfully halt or delay progression to type 2 diabetes in high-risk groups. ${ }^{3-5}$

On the basis of the results of these randomized trials, and the national demonstrator Greater Green Triangle Diabetes Prevention Program (DPP), ${ }^{7}$ along with economic modeling, the Council of Australian Governments in 2006 decided to invest in lifestyle modification programs for diabetes prevention. 
The Federal Government's program was targeted at adults aged $40-49$ years, and the state and territory programs targeted those aged 50 years and over. National standards for lifestyle modification programs were agreed on, and work started on an Australian tool for risk assessment (Australian Type 2 Diabetes Risk Assessment Tool, AUSDRISK) ${ }^{8}{ }^{9}$ to reflect the ethnic diversity of the contemporary Australian population. ${ }^{10}$ AUSDRISK is a 10-item questionnaire that estimates risk of progression to type 2 diabetes over 5 years. Its scoring includes questions based on age, sex, ethnicity, family history of diabetes, history of abnormal glucose metabolism, smoking status, current hypertensive treatment, physical activity, fruit and vegetable consumption, and waist circumference.

The Federal DPP was discontinued in 2011 due to poor recruitment and other implementation problems. ${ }^{11}$ The Victorian Life! program is a statewide DPP established by Diabetes Australia-Victoria in $2007 .{ }^{12}$ AUSDRISK was chosen as the screening tool for Life!, with an entry score of $\geq 15$ initially selected, but low recruitment rates led to a decision to lower the entry score to $\geq 12 .^{13}$ The Australian experience with AUSDRISK will be relevant to other countries wanting to develop a national instrument for screening.

Many other risk tools have been developed and validated to predict risk of type 2 diabetes, both in terms of current and future risk. These tools have been demonstrated to be effective and cost-effective in identification of individuals at high risk of developing type 2 diabetes, though their effectiveness may vary across different populations. ${ }^{14}$ Using a questionnaire such as AUSDRISK is a practical method to screen for high-risk individuals who might benefit from lifestyle modification, but it has been recommended that those found to be at high risk should also undergo an oral glucose tolerance test (OGTT) or glycated hemoglobin (HbA1c) to determine impairment of glucose metabolism and screen for undiagnosed diabetes. ${ }^{15}{ }^{16}$ Those found to have abnormal glucose metabolism should be invited to participate in lifestyle modification programs, while those with normal glucose metabolism should be provided with lifestyle advice and reassessed in 2-3 years. ${ }^{15-17}$

Best practice for recruitment and screening of individuals into real-world DPP remains uncertain. Given this knowledge gap and the implications for the effectiveness and cost-effectiveness, this paper evaluates the performance of AUSDRISK in identifying suitable candidates for entry into lifestyle modification programs.

\section{RESEARCH DESIGN AND METHODS}

\section{Sampling and collection}

The Greater Green Triangle Risk Factor Study (GGT RFS) consisted of three cross-sectional surveys of chronic disease risk factors carried out in Southwest Victoria from 2003 to 2006. This data set was chosen as the survey instrument had good agreement with biomedical and lifestyle questions relevant to AUSDRISK. Collection of data has been reported previously. ${ }^{18} 19$

\section{Inclusion and exclusion criteria}

Data from survey respondents aged 40-74 years were included for calculating AUSDRISK scores. Individuals who self-reported a previous diagnosis of diabetes, history of treatment with insulin, oral hypoglycemics or both were excluded from the analysis. Those with fasting plasma glucose $(\mathrm{FPG})>6.9 \mathrm{mmol} / \mathrm{L}$ were included in the study in order to evaluate the ability of AUSDRISK to detect those with undiagnosed diabetes in addition to IFG.

All participants had age and sex data available as they were selected from the electoral roll. Participants who did not have a waist circumference measurement were excluded from analysis, as a score could not be reliably imputed from the survey data.

\section{Treatment of missing values}

For AUSDRISK questions not related to waist circumference, missing values were assumed to score zero. A sensitivity analysis comparing total risk scores was undertaken with missing values imputed as zero versus cases excluded if there was at least one missing value.

\section{Conversion of data into risk scores}

Survey responses were coded into scores for AUSDRISK from the GGT RFS. Where survey questions did not directly match those of the screening tool, either the most similar question or a combination of questions was used to infer the most likely response. For example, in AUSDRISK question eight related to fruit and vegetable consumption, respondents were considered to score 0 (eat fruit everyday) if they reported eating vegetables or fruit 5-6 times per week or more.

\section{Definition of IFG and MetS}

The WHO definition of IFG $(6.1-6.9 \mathrm{mmol} / \mathrm{L})$ was used. ${ }^{20}$ The metabolic syndrome (MetS) was defined as per International Diabetes Federation (IDF) criteria, $^{21}$ with individuals required to have central obesity (defined by waist circumference with ethnicity specific values) plus any two of the following risk factors for diagnosis: raised triglycerides $(\geq 1.7 \mathrm{mmol} / \mathrm{L})$, reduced high-density lipoprotein cholesterol (males, <1.03; females, $<1.29 \mathrm{mmol} / \mathrm{L}$ ), raised blood pressure (systolic $\mathrm{BP} \geq 130$ or diastolic $\mathrm{BP} \geq 85 \mathrm{~mm} \mathrm{Hg}$ ) or raised FPG $(\geq 5.6 \mathrm{mmol} / \mathrm{L})$.

\section{Statistical analyses}

All analyses were performed in Stata V.13. Crude baseline demographic and biomedical measures were reported as mean values and SDs. Risk score stratifications were selected according to their reported risks of developing type 2 diabetes. $^{9}$ Annual incidence of type 2 diabetes for AUSDRISK categories was estimated using 
the reported risk of progression over 5 years assuming a constant yearly risk.

Proportions of the sample population were stratified by risk score, sex and age group. Estimates of the population in Victoria, Australia, were made at different cut-off scores using the estimated resident population in Victoria at 30 June $2014 .^{22}$ Sensitivity, specificity, positive predictive value (PPV), and negative predictive value were calculated for $\mathrm{FPG} \geq 6.1 \mathrm{mmol} / \mathrm{L}$ and stratified by risk score. Receiver operating characteristics (ROC) are also presented.

\section{RESULTS}

Of 1690 respondents in the GGT RFS, 1393 fulfilled age criteria. Of those, 129 were excluded due to lack of waist circumference measurements and a further 75 were omitted due to established diagnosis of diabetes, its treatment, or both. There was no significant difference between mean AUSDRISK scores when missing values were imputed as zero versus cases with missing values excluded from analysis. The results reported here are for those where missing values were assumed to score zero. Overall, AUSDRISK scores were calculated for 1189 individuals. Males were older than females and

Table 1 Characteristics of GGT RFS sample aged 40-74 years with a calculated AUSDRISK score

\begin{tabular}{llrl}
\hline Variable & N & Mean & (SD) \\
\hline Males & & & \\
Age (years) & 561 & 58.2 & $(9.5)$ \\
Weight (kg) & 560 & 87.6 & $(16.1)$ \\
BMI (kg/m²) & 560 & 28.5 & $(4.9)$ \\
Waist circumference (cm) & 561 & 100.4 & $(12.7)$ \\
FPG (mmol/L) & 519 & 5.4 & $(0.6)$ \\
Total cholesterol (mmol/L) & 547 & 5.4 & $(1.0)$ \\
HDL (mmol/L) & 547 & 1.3 & $(0.4)$ \\
LDL (mmol/L) & 534 & 3.3 & $(0.9)$ \\
Triglycerides (mmol/L) & 547 & 1.7 & $(1.1)$ \\
Systolic BP (mm Hg) & 561 & 135.2 & $(19.0)$ \\
Diastolic BP (mm Hg) & 561 & 80.5 & $(10.8)$ \\
AUSDRISK value & 561 & 12.9 & $(4.5)$ \\
Females & & & \\
Age (years) & 628 & 56.9 & $(9.5)$ \\
Weight (kg) & 628 & 74.9 & $(16.1)$ \\
BMI (kg/m²) & 625 & 28.5 & $(6.1)$ \\
Waist circumference (cm) & 628 & 89.8 & $(14.3)$ \\
FPG (mmol/L) & 586 & 5.2 & $(0.5)$ \\
Total cholesterol (mmol/L) & 600 & 5.6 & $(1.0)$ \\
HDL (mmol/L) & 600 & 1.6 & $(0.4)$ \\
LDL (mmol/L) & 597 & 3.3 & $(1.0)$ \\
Triglycerides (mmol/L) & 600 & 1.5 & $(0.7)$ \\
Systolic BP (mm Hg) & 628 & 131.1 & $(19.7)$ \\
Diastolic BP (mm Hg) & 626 & 75.4 & $(10.6)$ \\
AUSDRISK value & 628 & 10.3 & $(4.7)$ \\
\hline AUSR &
\end{tabular}

AUSDRISK, Australian Type 2 Diabetes Risk Assessment Tool; $\mathrm{BMI}$, body mass index; BP, blood pressure; FPG, fasting plasma glucose; GGT RFS, Greater Green Triangle Risk Factor Study; HDL, high-density lipoprotein; LDL, low-density lipoprotein. comprised a smaller proportion of the overall sample (table 1).

Overall, IFG prevalence was $4.7 \%$ (males 6.7\%; females $2.9 \%$ ). Mean body mass index (BMI) was similar in the overweight range for both genders (table 1). The MetS was present in $40.5 \%$ of males and $32.6 \%$ of females. Diabetic and cardiovascular risk factors, except total and low-density lipoprotein cholesterol, and also the presence of MetS demonstrated a significant linear trend when stratified by AUSDRISK group according to approximate risk of progression to diabetes (table 2).

Use of higher cut-off scores demonstrated increases in mean values of key diabetic risk factors (weight, BMI, waist circumference, FPG) (table 3).

The proportion of individuals included at different AUSDRISK cut-offs increased with age (table 4). Nearly $40 \%$ of the Victorian population aged $40-74$ years was estimated to have an AUSDRISK score of 12 or more, falling to approximately $5.2 \%$ at a cut-off score of 20 or higher (table 4).

After an AUSDRISK cut-off of $\geq 14$, the sum of sensitivity and specificity for detecting $\mathrm{FPG} \geq 6.1 \mathrm{mmol} / \mathrm{L}$ began to decline (table 5). ROC for detecting $\mathrm{FPG} \geq 6.1 \mathrm{mmol} / \mathrm{L}$ was 0.76 (95\% CI 0.70 to 0.81$)$.

\section{DISCUSSION}

Apart from the original Australian Diabetes, Obesity and Lifestyle study from which AUSDRISK was created, ${ }^{8}$ to the best of our knowledge, our study is the first that applies a detailed analysis of the risk tool to an Australian population to define different risk categories. We have evaluated AUSDRISK as a screening tool for lifestyle modification programs in Australia and found some important limitations that have international implications for policy and cost-effectiveness of such programs. Increases in AUSDRISK score categories were accompanied by increases in key biological risk factors for type 2 diabetes (table 2). Accordingly, using higher cut-off scores resulted in a higher proportion of individuals with obesity, central obesity, IFG and the MetS. These findings highlight the need to select a strategy for screening individuals into lifestyle modification programs to ensure that those who will benefit most are recruited.

For countries wishing to develop a national DPP, to determine the cut-off points for screening tools requires knowledge of the proportion of the population that will screen positive, and a minimum entry score should be selected to identify a feasible proportion of the population it is intended to reach (table 4). Based on our estimates, the current requirement of AUSDRISK $\geq 12$ would translate into $39.5 \%$ (916 000) of Victorians aged 4074 years being eligible to participate in the Life! program. Increasing the minimum score to $\geq 20$ reduces this proportion to $5.2 \%(120000)$. Using previously reported prevalence of IGT $(13.0 \%)$ and IFG (7.4\%) in Australia among adults aged $40-74$ years, ${ }^{23}$ 
Table 2 Diabetic and cardiovascular risk factors in GGT RFS by sex and AUSDRISK category

\begin{tabular}{|c|c|c|c|c|c|c|}
\hline \multirow[b]{2}{*}{ Annual incidence of type 2 diabetes (\%) } & \multicolumn{6}{|c|}{ AUSDRISK category } \\
\hline & $\begin{array}{l}0-5 \\
0.2\end{array}$ & $\begin{array}{l}6-8 \\
0.4 \\
\end{array}$ & $\begin{array}{l}9-11 \\
0.7\end{array}$ & $\begin{array}{l}12-15 \\
1.5\end{array}$ & $\begin{array}{l}16-19 \\
3.0\end{array}$ & $\begin{array}{l}20-36 \\
7.8\end{array}$ \\
\hline \multicolumn{7}{|l|}{ Males } \\
\hline Number of observations (\%) & $10(1.8)$ & $77(13.7)$ & $180(32.1)$ & $134(23.9)$ & $107(19.1)$ & $53(9.5)$ \\
\hline Age (years) & 41.8 & 47.8 & 57.2 & 61.0 & 61.5 & 65.5 \\
\hline Weight (kg) & 87.7 & 81.5 & 81.6 & 84.5 & 97.2 & 105.1 \\
\hline BMI $\left(\mathrm{kg} / \mathrm{m}^{2}\right)$ & 27.9 & 26.1 & 26.6 & 27.6 & 31.5 & 34.6 \\
\hline Waist circumference $(\mathrm{cm})$ & 92.2 & 91.6 & 94.4 & 98.8 & 110.6 & 118.8 \\
\hline $\mathrm{FPG}(\mathrm{mmol} / \mathrm{L})$ & 5.2 & 5.2 & 5.2 & 5.3 & 5.6 & 5.8 \\
\hline Total cholesterol (mmol/L) & 5.2 & 5.7 & 5.6 & 5.4 & 5.1 & 5.0 \\
\hline $\mathrm{HDL}(\mathrm{mmol} / \mathrm{L})$ & 1.4 & 1.4 & 1.4 & 1.3 & 1.2 & 1.2 \\
\hline $\mathrm{LDL}(\mathrm{mmol} / \mathrm{L})$ & 3.2 & 3.6 & 3.5 & 3.3 & 3.1 & 2.9 \\
\hline Triglycerides (mmol/L) & 1.3 & 1.5 & 1.6 & 1.7 & 1.9 & 2.0 \\
\hline Systolic BP (mm Hg) & 120.4 & 124.5 & 130.2 & 137.2 & 143.2 & 149.3 \\
\hline Diastolic BP (mm Hg) & 79.3 & 80.3 & 79.3 & 79.4 & 82.4 & 84.0 \\
\hline MetS (\%) & 11.1 & 14.7 & 26.8 & 41.6 & 64.9 & 83.3 \\
\hline \multicolumn{7}{|l|}{ Females } \\
\hline Number of observations (\%) & $98(15.6)$ & $161(25.6)$ & $117(18.6)$ & $154(24.5)$ & $75(11.9)$ & $23(3.7)$ \\
\hline Age (years) & 46.3 & 56.1 & 56.7 & 61.3 & 61.6 & 65.0 \\
\hline Weight (kg) & 65.2 & 67.5 & 74.1 & 80.0 & 88.8 & 92.4 \\
\hline $\operatorname{BMI}\left(\mathrm{kg} / \mathrm{m}^{2}\right)$ & 24.2 & 25.6 & 28.1 & 30.7 & 34.0 & 36.5 \\
\hline Waist circumference $(\mathrm{cm})$ & 77.8 & 81.6 & 88.0 & 96.9 & 104.6 & 113.2 \\
\hline FPG (mmol/L) & 4.9 & 5.0 & 5.1 & 5.2 & 5.5 & 5.7 \\
\hline Total cholesterol (mmol/L) & 5.1 & 5.8 & 5.5 & 5.9 & 5.5 & 5.3 \\
\hline $\mathrm{HDL}(\mathrm{mmol} / \mathrm{L})$ & 1.8 & 1.8 & 1.6 & 1.6 & 1.4 & 1.4 \\
\hline $\mathrm{LDL}(\mathrm{mmol} / \mathrm{L})$ & 2.8 & 3.4 & 3.2 & 3.5 & 3.2 & 3.1 \\
\hline Triglycerides (mmol/L) & 1.0 & 1.2 & 1.5 & 1.8 & 1.9 & 1.9 \\
\hline Systolic BP (mm Hg) & 117.0 & 126.3 & 132.0 & 137.8 & 141.1 & 141.2 \\
\hline Diastolic BP (mm Hg) & 71.7 & 74.3 & 77.3 & 76.7 & 77.8 & 73.4 \\
\hline MetS (\%) & 4.4 & 11.8 & 28.3 & 53.1 & 64.7 & 89.5 \\
\hline
\end{tabular}

AUSDRISK, Australian Type 2 Diabetes Risk Assessment Tool; BMI, body mass index; BP, blood pressure; FPG, fasting plasma glucose; GGT RFS, Greater Green Triangle Risk Factor Study; HDL, high-density lipoprotein; LDL, low-density lipoprotein; MetS, metabolic syndrome.

approximately 154000 and 87000 Victorians in this age group would be expected to have IGT and IFG, respectively. From 2007 to 2011, Life! received 29000 referrals with 8412 initiating the program, and 3114 completed session 1 and session $6 .{ }^{12}$ Life! was recently reported to have received an updated total of 59000 referrals. $^{24}$ Given these numbers, the impact of the Life! program has likely been diluted by targeting those at comparatively lower risk of developing type 2 diabetes (ie, AUSDRISK $\geq 12$ ), and would have a greater impact if delivered exclusively to those with abnormal glucose metabolism.

As the prevalence of IFG in our sample $(4.7 \%)$ and the Australian population ${ }^{23}$ is relatively low, even at a cut-off of AUSDRISK $\geq 20$, the PPV for detecting $\mathrm{FPG} \geq 6.1 \mathrm{mmol} / \mathrm{L}$ was $28.4 \%$. Although $2 \mathrm{~h}$ postglucose load data was not collected in this study, with the prevalence of IGT or IFG previously estimated at $16.4 \%,{ }^{23}$ the expected PPV for detecting IGT or IFG would be slightly greater than that for IFG alone. These results demonstrate that a diabetes risk assessment tool alone cannot be used to determine glucose metabolism status, and additional testing with OGTT, fasting glucose, or HbAlc is required for those who are identified to be at elevated risk of progressing to type 2 diabetes, as suggested by international guidelines. ${ }^{15} 16$ Previous research has also demonstrated that this two-stage screening strategy is a more cost-effective method to identify individuals with undiagnosed diabetes, IFG and IGT than laboratory testing alone. ${ }^{25}$ Even though clinicians may opt to proceed directly to laboratory testing, setting an appropriate and cost-effective cut-off score for entry to lifestyle modification programs is important, given that Life! has seen a significant proportion of individuals recruited through a variety of methods not involving physicians or other health professionals. ${ }^{12}$

Early involvement of family physicians represents an important opportunity to identify additional comorbidities and chronic disease risk factors. Our results demonstrate that a significant proportion of individuals at high risk of progressing to type 2 diabetes also have key cardiovascular risk factors including hypertension, hypercholesterolemia, and MetS (table 3). Previous research has demonstrated the existence of treatment gaps in treatment of hypertension and dyslipidemia among those participating in lifestyle modification programs. ${ }^{26}$ 
Table 3 Characteristics of GGT RFS participants included at different AUSDRISK cut-off values by sex

\begin{tabular}{|c|c|c|c|c|c|c|}
\hline & \multicolumn{6}{|c|}{ AUSDRISK cut-off } \\
\hline & \multicolumn{3}{|c|}{ Males } & \multicolumn{3}{|c|}{ Females } \\
\hline & $\geq 12$ & $\geq 16$ & $\geq \mathbf{2 0}$ & $\geq 12$ & $\geq 16$ & $\geq \mathbf{2 0}$ \\
\hline Age (years) & 62.0 & 62.8 & 65.5 & 61.7 & 62.4 & 65.0 \\
\hline Weight (kg) & 92.8 & 99.8 & 105.1 & 83.8 & 89.7 & 92.4 \\
\hline BMI $\left(\mathrm{kg} / \mathrm{m}^{2}\right)$ & 30.3 & 32.5 & 34.6 & 32.2 & 34.6 & 36.5 \\
\hline 25 to $<30(\%)$ & 42.5 & 29.4 & 17.0 & 30.6 & 21.4 & 21.7 \\
\hline$\geq 30(\%)$ & 46.6 & 68.1 & 83.0 & 61.1 & 75.5 & 78.3 \\
\hline Waist circumference $(\mathrm{cm})$ & 106.7 & 113.3 & 118.8 & 100.6 & 106.6 & 113.2 \\
\hline Male 94 to $<102$; female 80 to $<88(\%)$ & 18.7 & 5.6 & 1.9 & 4.8 & 3.1 & 0.0 \\
\hline Male $\geq 102 ;$ female $\geq 88(\%)$ & 71.4 & 92.5 & 98.1 & 90.1 & 94.9 & 100.0 \\
\hline $\mathrm{FPG}(\mathrm{mmol} / \mathrm{L})$ & 5.5 & 5.7 & 5.8 & 5.4 & 5.6 & 5.7 \\
\hline $6.1-6.9(\%)$ & 11.2 & 13.4 & 20.8 & 4.4 & 3.5 & 10.5 \\
\hline$\geq 7.0(\%)$ & 3.4 & 5.6 & 8.3 & 2.2 & 5.8 & 5.3 \\
\hline Total cholesterol (mmol/L) & 5.2 & 5.1 & 5.0 & 5.7 & 5.5 & 5.3 \\
\hline$\geq 5.5(\%)$ & 42.2 & 36.9 & 30.2 & 56.4 & 48.0 & 34.8 \\
\hline $\mathrm{HDL}(\mathrm{mmol} / \mathrm{L})$ & 1.3 & 1.2 & 1.2 & 1.5 & 1.4 & 1.4 \\
\hline Male <1.0; female <1.3 (\%) & 15.7 & 20.0 & 20.8 & 22.6 & 27.6 & 34.8 \\
\hline $\mathrm{LDL}(\mathrm{mmol} / \mathrm{L})$ & 3.2 & 3.0 & 2.9 & 3.4 & 3.2 & 3.1 \\
\hline$\geq 3.5(\%)$ & 35.4 & 31.9 & 26.4 & 40.9 & 33.7 & 13.0 \\
\hline Triglycerides (mmol/L) & 1.8 & 1.9 & 2.0 & 1.8 & 1.9 & 1.9 \\
\hline$\geq 2.0(\%)$ & 30.3 & 35.6 & 41.5 & 33.7 & 42.9 & 43.5 \\
\hline Systolic BP (mm Hg) & 141.6 & 145.2 & 149.3 & 139.1 & 141.1 & 141.2 \\
\hline$\geq 140(\%)$ & 52.0 & 59.4 & 69.8 & 44.4 & 50.0 & 52.2 \\
\hline Diastolic BP (mm Hg) & 81.4 & 83.0 & 84.0 & 76.7 & 76.8 & 73.4 \\
\hline$\geq 90(\%)$ & 23.1 & 26.9 & 28.3 & 11.9 & 12.2 & 4.4 \\
\hline MetS (\%) & 57.3 & 71.1 & 83.3 & 59.6 & 70.1 & 89.5 \\
\hline
\end{tabular}

AUSDRISK, Australian Type 2 Diabetes Risk Assessment Tool; BMI, body mass index; BP, blood pressure; FPG, fasting plasma glucose; GGT RFS, Greater Green Triangle Risk Factor Study; HDL, high-density lipoprotein; LDL, low-density lipoprotein; MetS, metabolic syndrome.

Therefore, in addition to lifestyle modification, addressing these risk factors is essential to reducing future disease burden, as cardiovascular disease contributes disproportionately to the morbidity as a result of diabetes. ${ }^{27}$

The baseline risk of diabetes among participants in lifestyle modification programs has important implications for the cost-effectiveness. Those at highest risk of progressing to type 2 diabetes represent the greatest potential for absolute reduction of incident cases of type 2 diabetes. A meta-analysis of 30 studies found that annual rate of progression to diabetes was $10-15 \%$ in those with IGT and IFG, 4.4-6.4\% in those with isolated IGT, and $6.1-9.2 \%$ in those with isolated IFG. $^{6}$ These values are similar to the estimated annual rate of progression to type 2 diabetes for those scoring AUSDRISK $\geq 20$ (7.8\%). Eligibility requirements for Life! should therefore include those with IGT, IFG, or both.

On the basis of the results of the Finnish Diabetes Prevention Study (DPS) ${ }^{28}{ }^{29}$ and the US DPP, ${ }^{5}{ }^{30}$ the Life! program was estimated to potentially reduce risk of progression to type 2 diabetes by $21-39 \%$ at 8 months. ${ }^{12}$ However, these results are not necessarily generalizable to Life!, as participants in both the Finnish and US studies had diagnosed IGT. Even if the relative risk reduction is similar among risk groups, a lower baseline risk translates to decreased absolute risk reduction and therefore decreased cost-effectiveness.

A cost-effectiveness analysis is required to assess the economic implications of various entry requirements into lifestyle intervention programs. Multiple studies have reported lifestyle modification programs to be costeffective in participants with IGT or IFG. ${ }^{31-33}$ However, cost-effectiveness of lifestyle modification programs has not been reported in individuals without abnormal glucose metabolism but nonetheless are at elevated risk of developing type 2 diabetes.

A limitation of our study is lack of OGTT or HbA1c data. As stated above, based on the prevalence of IFG and IGT, the PPV for detecting IGT would be expected to greater than that for IFG. While there is overlap between those with IGT and IFG, there remains a significant proportion of individuals with IGT who have normal FPG values. ${ }^{23}$ Our study therefore does not wholly evaluate the ability of AUSDRISK to identify individuals who would benefit from lifestyle modification programs. Further study is warranted on the performance of AUSDRISK in the detection of IGT, elevated HbA1c, and undiagnosed diabetes where OGTT and HbA1c data are available from an Australian population. This research would complement our current study to identify a suitable AUSDRISK cut-off score for entry into 
Table 4 Proportion of GGT RFS included at different AUSDRISK cut-off values by age and sex

\begin{tabular}{|c|c|c|c|c|c|c|}
\hline \multirow[b]{2}{*}{ Age (years) } & \multirow[b]{2}{*}{$\mathbf{N}$} & \multicolumn{5}{|l|}{ AUSDRISK cut-off } \\
\hline & & $\geq 12$ & $\geq 14$ & $\geq 16$ & $\geq 18$ & $\geq 20$ \\
\hline \multicolumn{7}{|l|}{ Males } \\
\hline 40-49 & 128 & 23.4 & 14.1 & 7.0 & 1.6 & 0.0 \\
\hline $50-59$ & 184 & 46.7 & 32.1 & 25.0 & 14.1 & 4.3 \\
\hline $60-69$ & 170 & 68.2 & 55.9 & 42.9 & 26.5 & 18.8 \\
\hline $70-74$ & 79 & 78.5 & 55.7 & 40.5 & 26.6 & 16.5 \\
\hline Total & 561 & 52.4 & 38.5 & 28.5 & 16.8 & 9.4 \\
\hline \multicolumn{7}{|l|}{ Females } \\
\hline 40-49 & 182 & 14.8 & 9.3 & 5.5 & 0.5 & 0.5 \\
\hline $50-59$ & 189 & 36.5 & 21.7 & 13.8 & 5.3 & 2.6 \\
\hline $60-69$ & 187 & 60.4 & 38.5 & 22.5 & 8.0 & 4.8 \\
\hline $70-74$ & 70 & 61.4 & 52.9 & 28.6 & 12.9 & 11.4 \\
\hline Total & 628 & 40.1 & 26.6 & 15.6 & 5.6 & 3.7 \\
\hline \multicolumn{7}{|l|}{ Overall } \\
\hline $40-49$ & 310 & 18.4 & 11.3 & 6.1 & 1.0 & 0.3 \\
\hline $50-59$ & 373 & 41.6 & 26.8 & 19.3 & 9.7 & 3.5 \\
\hline $60-69$ & 357 & 64.1 & 46.8 & 32.2 & 16.8 & 11.5 \\
\hline $70-74$ & 149 & 70.5 & 54.4 & 34.9 & 20.1 & 14.1 \\
\hline Total & 1189 & 45.9 & 32.2 & 21.7 & 10.8 & 6.4 \\
\hline \multicolumn{7}{|c|}{ Population estimates in Victoria, Australia, aged $40-74$ years } \\
\hline $\begin{array}{l}\text { Number of persons } \\
(000 \mathrm{~s})(95 \% \mathrm{Cl})\end{array}$ & & 916 (859 to 974$)$ & 637 (583 to 690$)$ & 425 (379 to 472$)$ & 208 (174 to 243$)$ & 120 (93 to 146$)$ \\
\hline $\begin{array}{l}\text { Proportion of } \\
\text { population }(95 \% \mathrm{Cl})\end{array}$ & & 39.5 (37.0 to 42.0$)$ & 27.5 (25.2 to 29.8$)$ & $18.3(16.3$ to 20.4$)$ & $9.0(7.5$ to 10.5$)$ & $5.2(4.0$ to 6.3$)$ \\
\hline
\end{tabular}

Data are percentages unless otherwise stated.

AUSDRISK, Australian Type 2 Diabetes Risk Assessment Tool; GGT RFS, Greater Green Triangle Risk Factor Study.

Life! or any subsequent national DPP. Analysis of AUSDRISK performance in relation to detecting elevated HbAlc levels is particularly significant given the future transition away from performing OGTT and towards HbAlc and FPG testing.

Data in the GGT RFS was collected in Southwest Victoria from 2004 to 2006 . There were no systematic differences in the prevalence of IFG, MetS, and obesity among age and gender groups to those reported in the Victorian Health Monitor, a cross-sectional population health measurement survey collected between May 2009 and April 2010. ${ }^{34}$ This suggests our sample for the purpose of these analyses remains a satisfactory indicator of population health characteristics in Victoria.

This paper has focused exclusively on the performance of AUSDRISK as a screening tool to identify those who would benefit from a lifestyle modification programs to prevent type 2 diabetes. It is important to consider that an effective screening method is only one aspect of implementing lifestyle modification programs to stop or delay the progression to type 2 diabetes. Lifestyle modification programs need to demonstrate

Table 5 Characteristics of AUSDRISK using various cut-off values for detecting abnormal fasting glucose

\begin{tabular}{lllll}
\hline FPG $\geq 6.1$ mmol/L & & & \\
\hline AUSDRISK cut-off & Sensitivity & Specificity & PPV & NPV \\
\hline$\geq 12$ & $81.3(70.7$ to 89.4$)$ & $57.7(54.6$ to 60.7$)$ & $12.3(9.5$ to 15.5$)$ & $97.7(96.2$ to 98.7$)$ \\
$\geq 13$ & $74.7(63.3$ to 84.0$)$ & $63.8(60.8$ to 66.7$)$ & $13.1(10.0$ to 16.6$)$ & $97.2(95.6$ to 98.3$)$ \\
$\geq 14$ & $68.0(56.2$ to 78.3$)$ & $71.6(68.7$ to 74.3$)$ & $14.8(11.2$ to 19.0$)$ & $96.8(95.3$ to 98.0$)$ \\
$\geq 15$ & $61.3(49.4$ to 72.4$)$ & $76.4(73.7$ to 79.0$)$ & $15.9(11.9$ to 20.7$)$ & $96.4(94.9$ to 97.6$)$ \\
$\geq 16$ & $53.3(41.4$ to 64.9$)$ & $81.7(79.1$ to 84.0$)$ & $17.5(12.8$ to 23.0$)$ & $96.0(94.5$ to 97.2$)$ \\
$\geq 17$ & $45.3(33.8$ to 57.3$)$ & $86.3(84.1$ to 88.4$)$ & $19.4(13.8$ to 26.1$)$ & $95.6(94.1$ to 96.8$)$ \\
$\geq 18$ & $34.7(24.0$ to 46.5$)$ & $91.7(89.9$ to 93.4$)$ & $23.4(15.9$ to 32.4$)$ & $95.1(93.5$ to 96.3$)$ \\
$\geq 19$ & $28.0(18.2$ to 39.6$)$ & $94.6(93.0$ to 95.9$)$ & $27.3(17.7$ to 38.6$)$ & $94.7(93.2$ to 96.0$)$ \\
$\geq 20$ & $25.3(16.0$ to 36.7$)$ & $95.3(93.9$ to 96.5$)$ & $28.4(18.0$ to 40.7$)$ & $94.6(93.1$ to 95.9$)$ \\
\hline
\end{tabular}

Data are \% $(95 \% \mathrm{Cl})$.

AUSDRISK, Australian Type 2 Diabetes Risk Assessment Tool; FPG, fasting plasma glucose; NPV, negative predictive value; PPV, positive predictive value. 
effectiveness in reducing the progression to type 2 diabetes, and promote sustainable lifestyle changes so that effects are persistent in the long term. Moreover, lifestyle modification programs represent one part of a targeted approach to reducing the burden of type 2 diabetes, that ideally should be accompanied by a range of population-level approaches to diabetogenic environments. ${ }^{35}{ }^{36}$ Where lifestyle medication programs are not available, screening individuals for risk of developing type 2 diabetes remains warranted, provided that simple lifestyle advice is provided and appropriate follow-up testing for those at high risk is offered, where appropriate.

Our findings indicate that revisiting entry criteria into Life! is timely. Relying on AUSDRISK at a relatively low cut-off, while recruiting large numbers of people, hinders the long-term effectiveness of the program. A multifaceted approach is required. Initial screening with AUSDRISK, followed by OGTT, fasting glucose, or HbA1c for those at high risk to detect IFG, IGT, and undiagnosed diabetes is needed. Those with IFG and IGT should be invited into Life!, while those at high risk but with normal glucose metabolism should be offered lifestyle information and rescreened in the following 3 years. To reliably establish and justify these thresholds, economic modeling is required to determine the most effective strategy.

\section{Author affiliations \\ ${ }^{1}$ Greater Green Triangle University Department of Rural Health, Flinders and Deakin Universities, Warrnambool, Victoria, Australia \\ ${ }^{2}$ Western Centre for Health Research and Education, Western Health, University of Melbourne, St. Albans, Victoria, Australia \\ ${ }^{3}$ National Institute for Health and Welfare, Helsinki, Finland \\ ${ }^{4}$ Faculty of Health Sciences, Institute of Public Health and Clinical Nutrition, University of Eastern Finland, Kuopio, Finland \\ ${ }^{5}$ Faculty of Health, Deakin Population Health Strategic Research Centre, Deakin University, Burwood, Australia}

Acknowledgements The authors thank Ms Anna Chapman, Dr Andrew Baird, the nurses who carried out the survey and the regional hospitals that provided facilities for the original GGT RFS study.

Contributors JAM helped conceived the idea, conducted the literature search, performed the data analysis, and wrote the manuscript. VLV helped conceive the idea, provided statistical support and wrote the manuscript. EDJ contributed to the discussion. TL, MP and MJC contributed to the results and discussion. EV contributed to the results. JAD conceived the idea and wrote the manuscript. All authors reviewed and edited the manuscript. JAM is the guarantor.

Funding The original GGT RFS study was supported by the Australian Government Department of Health and Ageing, the Australian Health Ministers' Advisory Council (Priority Driven Research in Population Health grant number 01/14), the Royal Australian College of General Practitioners, Sanofi-Aventis, Pfizer, Roche Diagnostics and Servier Laboratories Australia JAM completed this research as part of a placement at GGT UDRH through the Specialist Training Program funded by the Royal Australasian College of Physicians

Competing interests None declared.

Ethics approval Flinders University Clinical Research Ethics Committee, Adelaide, approval number 207/034

Provenance and peer review Not commissioned; externally peer reviewed.
Data sharing statement No additional data are available.

Open Access This is an Open Access article distributed in accordance with the Creative Commons Attribution Non Commercial (CC BY-NC 4.0) license, which permits others to distribute, remix, adapt, build upon this work noncommercially, and license their derivative works on different terms, provided the original work is properly cited and the use is non-commercial. See: http:// creativecommons.org/licenses/by-nc/4.0/

\section{REFERENCES}

1. Guariguata L, Whiting DR, Hambleton I, et al. Global estimates of diabetes prevalence for 2013 and projections for 2035. Diabetes Res Clin Pract 2014;103:137-49.

2. Lee CM, Colagiuri R, Magliano DJ, et al. The cost of diabetes in adults in Australia. Diabetes Res Clin Pract 2013;99:385-90.

3. Pan XR, Li GW, Hu YH, et al. Effects of diet and exercise in preventing NIDDM in people with impaired glucose tolerance: the $\mathrm{Da}$ Qing IGT and Diabetes Study. Diabetes Care 1997;20:537-44.

4. Tuomilehto J, Lindström J, Eriksson JG, et al. Prevention of type 2 diabetes mellitus by changes in lifestyle among subjects with impaired glucose tolerance. N Engl J Med 2001;344:1343-50.

5. Knowler WC, Barrett-Connor E, Fowler SE. Diabetes Prevention Program Research Group. Reduction in the incidence of type 2 diabetes with lifestyle intervention or metformin. N Engl J Med 2002;346:393-403.

6. Gerstein HC, Santaguida P, Raina P, et al. Annual incidence and relative risk of diabetes in people with various categories of dysglycemia: a systematic overview and meta-analysis of prospective studies. Diabetes Res Clin Pract 2007;78:305-12.

7. Laatikainen T, Dunbar J, Chapman A, et al. Prevention of type 2 diabetes by lifestyle intervention in an Australian primary health care setting: Greater Green Triangle (GGT) Diabetes Prevention Project. BMC Public Health 2007;7:249.

8. Chen L, Magliano DJ, Balkau B, et al. AUSDRISK: an Australian Type 2 Diabetes Risk Assessment Tool based on demographic, lifestyle and simple anthropometric measures. Med J Aust 2010;192:197.

9. Australian Government Department of Health and Ageing. The Australian Type 2 Diabetes Risk Assessment Tool (AUSDRISK). Secondary The Australian Type 2 Diabetes Risk Assessment Tool (AUSDRISK). 2013 July 2008. http://www.health.gov.au/ preventionoftype2diabetes

10. Council of Australian Governments. COAG National Reform Agenda Consultation Draft, 2006:31-2.

11. Colagiuri S, Johnson G. Case for action proposal: a comprehensive type 2 diabetes prevention program. National Health and Medical Research Council Research Translation Faculty, 2015.

12. Dunbar JA, Jayawardena A, Johnson G, et al. Scaling up diabetes prevention in Victoria, Australia: policy development, implementation, and evaluation. Diabetes Care 2014;37:934-42.

13. Colagiuri R, Girgis S, Gomez M, et al. National evidence based guideline for the primary prevention of type 2 diabetes. Canberra: Diabetes Australia and the NHMRC, 2009.

14. Schwarz P, Li J, Lindstrom J, et al. Tools for predicting the risk of type 2 diabetes in daily practice. Horm Metab Res 2009;41:86-97.

15. Paulweber B, Valensi P, Lindström J, et al. A European evidence-based guideline for the prevention of type 2 diabetes. Horm Metab Res 2010;42(Suppl 1):S3-36.

16. National Institute for Health and Clinical Excellence. Preventing type 2 diabetes: risk identification and interventions for individuals at high risk. London: National Intitute for Health and Clinical Excellence, 2012.

17. Diabetes Prevention Working Party. Prevention of type 2 diabetes: a background paper. Secondary Prevention of type 2 diabetes: a background paper. 2005. http://www.health.vic.gov.au/archive/ archive2014/nphp/publications/a_z.htm

18. Janus ED, Laatikainen T, Dunbar J, et al. Overweight, obesity and metabolic syndrome in rural southeastern Australia. Med J Aust 2007; 187:147-52.

19. Janus E, Bunker S, Kilkkinen A, et al. Prevalence, detection and drug treatment of hypertension in a rural Australian population: the Greater Green Triangle Risk Factor Study 2004-2006. Intern Med J 2008:38:879-86.

20. World Health Organization. Definition and diagnosis of diabetes mellitus and intermediate hyperglycemia: report of a WHO/IDF consultation. Geneva: World Health Organization, 2006.

21. International Diabetes Federation. The IDF consensus worldwide definition of the metabolic syndrome. Brussels, Belgium: International Diabetes Federation, 2006. 
22. Australian Bureau of Statistics. Australian demographic statistics. Secondary Australian demographic statistics. 2014. http://www.abs. gov.au/AUSSTATS/abs@.nsf/DetailsPage/3101.0Sep2014? OpenDocument

23. Dunstan DW, Zimmet PZ, Welborn TA, et al. The rising prevalence of diabetes and impaired glucose tolerance: the Australian Diabetes, Obesity and Lifestyle study. Diabetes Care 2002;25:829-34.

24. Johnson G, Martin J, Timoshanko A. Preventing type 2 diabetes: scaling up to create a prevention system. Med $J$ Aust 2015;202:24-6.

25. Khunti K, Gillies CL, Taub NA, et al. A comparison of cost per case detected of screening strategies for type 2 diabetes and impaired glucose regulation: modelling study. Diabetes Res Clin Pract 2012;97:505-13.

26. McNamara K, Philpot B, Janus ED, et al. Greater Green Triangle Diabetes Prevention Program: remaining treatment gaps in hypertension and dyslipidaemia. Aust J Rural Health 2010;18:43-4.

27. Barr EL, Zimmet PZ, Welborn TA, et al. Risk of cardiovascular and all-cause mortality in individuals with diabetes mellitus, impaired fasting glucose, and impaired glucose tolerance: the Australian Diabetes, Obesity, and Lifestyle Study (AusDiab). Circulation 2007;116:151-7.

28. Ilanne-Parikka P, Eriksson JG, Lindström J, et al. Effect of lifestyle intervention on the occurrence of metabolic syndrome and its components in the Finnish Diabetes Prevention Study. Diabetes Care 2008;31:805-7.

29. Lindström J, llanne-Parikka P, Peltonen M, et al. Sustained reduction in the incidence of type 2 diabetes by lifestyle intervention: follow-up of the Finnish Diabetes Prevention Study. Lancet 2006;368:1673-9.

30. Knowler WC, Fowler SE, Hamman RF. Diabetes Prevention Program Research Group. 10-year follow-up of diabetes incidence and weight loss in the Diabetes Prevention Program Outcomes Study. Lancet 2009;374:1677-86.

31. Bertram M, Lim S, Barendregt J, et al. Assessing the cost-effectiveness of drug and lifestyle intervention following opportunistic screening for pre-diabetes in primary care. Diabetologia 2010;53:875-81.

32. Palmer AJ, Roze S, Valentine WJ, et al. Intensive lifestyle changes or metformin in patients with impaired glucose tolerance: modeling the long-term health economic implications of the diabetes prevention program in Australia, France, Germany, Switzerland, and the United Kingdom. Clin Ther 2004;26:304-21.

33. Jacobs-van der Bruggen MA, Bos G, Bemelmans WJ, et al. Lifestyle interventions are cost-effective in people with different levels of diabetes risk: results from a modeling study. Diabetes Care 2007;30:128-34.

34. Department of Health. The Victorian Health Monitor. Melbourne: State Government of Victoria, 2012.

35. Lindström J, Neumann A, Sheppard K, et al. Take action to prevent diabetes-the IMAGE toolkit for the prevention of type 2 diabetes in Europe. Horm Metab Res 2010;42:S37-55.

36. Schwarz PE, Greaves CJ, Lindström J, et al. Nonpharmacological interventions for the prevention of type 2 diabetes mellitus. Nat Rev Endocrinol 2012;8:363-73. 